\title{
Estudo das percepções de docentes e discentes sobre a aplicação de metodologias ativas em disciplinas de graduação em Engenharia Civil
}

\author{
Study of perceptions of teachers and students about the application of active \\ methodologies in Civil Engineering Course
}

\author{
Amanda Furlin Renosto orcid.org/0000-0001-6264-8716 \\ Universidade Federal de Santa Maria - Laboratório de Mobilidade e Logística (LAMOT) \\ E-mail: amanda.renosto@acad.ufsm.br \\ Luiza Pereira Antunes (iD orcid.org/0000-0003-2137-4629 \\ Universidade Federal de Santa Maria - Laboratório de Mobilidade e Logística (LAMOT) \\ E-mail: luiza.antunes@acad.ufsm.br \\ Eloísa Moura Somavilla (iD orcid.org/0000-0002-7180-3666 \\ Universidade Federal de Santa Maria - Laboratório de Mobilidade e Logística (LAMOT) \\ E-mail: somavillaeloisa@gmail.com
}

\begin{abstract}
Alejandro Ruiz-Padillo (i) orcid.org/0000-0001-8313-0916
Universidade Federal de Santa Maria - Laboratório de Mobilidade e Logística (LAMOT)

E-mail: alejandro.ruiz-padillo@ufsm.br
\end{abstract}

\section{Resumo}

O processo de ensino-aprendizagem nos cursos de engenharia passa por inúmeros desafios atualmente. As contínuas mudanças tecnológicas, juntamente com a desmotivação dos estudantes, demonstram a necessidade de recursos didático-pedagógicos mais atrativos e alinhados às exigências do mercado de trabalho. Além disso, as adaptações ao ensino remoto nas universidades, motivadas pela pandemia de COVID-19, enfatizaram a importância da evolução dos métodos de ensinoaprendizagem. Dessa forma, as metodologias ativas mostram-se grandes aliadas para a modernização da sala de aula e para a melhoria no desempenho acadêmico e desenvolvimento de novas competências por parte dos discentes. Assim, este trabalho teve como objetivo analisar as percepções tanto de graduandos como de docentes sobre as experiências de utilização de metodologias ativas de ensino-aprendizagem no curso de Engenharia Civil da Universidade Federal de Santa Maria, RS, e identificar as mudanças na aplicação e nos resultados alcançados entre os formatos presencial e remoto. Para tal, as opiniões de professores e alunos foram obtidas mediante a aplicação de questionários e realização de entrevistas, e as respostas foram analisadas com ferramentas estatísticas e de avaliação qualitativa de nuvens de palavras. Assim, percebeu-se que grande parte dos docentes compreendem a importância das metodologias ativas e aplicam diferentes tipos nas disciplinas, e que os estudantes reconheceram uma contribuição positiva na aprendizagem, mostrando interesse na experimentação ativa, resolução de problemas e trabalhos em grupo. Porém, evidenciaram-se dificuldades na implementação das metodologias e limitações para alcançar os objetivos pretendidos, assim como alterações nos recursos didático-pedagógicos empregados devido à migração para o formato remoto. 
Palavras-chave: Técnicas de Ensino-Aprendizagem. Ensino de graduação. Percepção. Prática em Situação Real.

\begin{abstract}
The teaching-learning process in engineering courses currently faces numerous challenges. The continuous technological changes, together with the students' demotivation, demonstrate the need for more attractive educational resources, also in line with the demands of the labor market. In addition, adaptations to distance teaching at universities, caused by the pandemic of COVID-19, emphasized the importance of the evolution of teaching-learning methods. Therefore, active methodologies have a leading role to modernize the classroom and to allow students to improve their academic performance and to develop new skills. Thus, this work aimed to analyze the perceptions of professors and students about experiences of using active teaching-learning methodologies in the Civil Engineering course at the Federal University of Santa Maria, RS, Brazil, and to identify changes in the application and results achieved between face-to-face and distance teaching. To this end, the opinions of professors and students were obtained by applying questionnaires and interviews, and the responses were analyzed using statistical tools and qualitative assessment of word clouds. As a result, most teachers understood the importance of active methodologies and applied different types in the course subjects. Meanwhile, students showed interest in active experimentation, problem solving and group work, and recognized a positive contribution to learning. Nonetheless, difficulties were reported in the implementation of the methodologies, as well as limitations to achieve the intended objectives and changes in the educational resources employed, due to the migration to distance teaching.
\end{abstract}

Keywords: Teaching Methods. Undergraduate Study. Perception. Evidence Based Practice

\title{
Introdução
}

Os constantes avanços tecnológicos e científicos nas diversas áreas ligadas à engenharia exigem a incorporação de mudanças no ensino tradicionalmente vigente nesses cursos. Além disso, as necessidades do mercado de trabalho para a formação desses profissionais são ainda mais severas, de forma a tornarem indispensáveis, além de uma boa formação técnica, qualificações e características pessoais de ética, boa conduta, comunicação e criatividade (STEFANELLO et al., 2020). Nos métodos tradicionais de ensino-aprendizagem, onde o conhecimento é transmitido aos estudantes de forma expositiva em sala de aula, dificilmente essas competências são desenvolvidas. Dessa forma, nos últimos anos, novas abordagens de ensino vêm ganhando espaço no meio acadêmico, as denominadas metodologias ativas, nas quais o estudante se configura como principal agente de construção do seu conhecimento (PRINCE, 2004).

Nesse contexto, as metodologias ativas de ensino-aprendizagem se destacam atualmente por um aprendizado mais efetivo devido às atividades e experiências desenvolvidas pelos alunos (KOLHEKAR; SHAH; JADJAV, 2021). Como a própria denominação do termo ressalta, essas novas metodologias removem do estudante o papel passivo, tornando-o responsável pela sua aprendizagem. Nessa abordagem, o professor se configura como um auxiliador, e o estudante recebe o foco principal, o que traz a ele maior autonomia em relação a sua aprendizagem e desenvolvimento racional (STEFANELLO et al., 2020).

Deshpande e Huang (2011) reportam que a utilização de metodologias ativas de ensino-aprendizagem e atividades práticas gera melhorias no desempenho acadêmico e avaliativo dos estudantes, colaborando com a atenuação de problemas evidenciados no ensino superior, como, por exemplo, o índice de evasão elevado observado nos cursos de engenharia. Dessa forma, o dinamismo e a animosidade em 
sala de aula se configuram como fatores muito importantes para um processo de aprendizado mais agradável e estimulante aos estudantes (BARBOSA; MOURA, 2014; JEONG et al., 2019).

Por outro lado, a pandemia de COVID-19 e o processo de adequação ao ensino remoto para a conservação das atividades nas universidades intensificaram os problemas já existentes e novamente colocaram em pauta a necessidade de modernização desse sistema. Com a suspensão das atividades presenciais nas universidades, foi necessária a adaptação repentina tanto dos estudantes quanto dos professores, que, mesmo sem a interação em sala de aula, foram desafiados a manter a qualidade e o nível de aprendizado mediante o uso da internet, em um momento delicado de incertezas e temores sobre o futuro (COSTA, 2020; JEONG et al., 2019; KOLHEKAR; SHAH; JADJAV, 2021; IGLESIAS-PRADAS et al., 2021; SANTIAGO et al., 2021).

Nessa nova realidade para o ensino em geral e também para os cursos de engenharia, as metodologias de ensino-aprendizagem foram obrigadas igualmente a migrar para a formato remoto mediante o uso de Tecnologias em Rede, o que evidenciou ainda mais as deficiências dos métodos tradicionais, especialmente em relação às avaliações, que historicamente nas engenharias são realizadas de forma presencial (IGLESIAS-PRADAS et al., 2021). Portanto, estas bruscas mudanças tornaram todo o contexto ainda mais problemático e desafiador aos envolvidos. No entanto, de acordo com Costa (2020), a atual situação está possibilitando uma nova experiência para a educação com a utilização da tecnologia e demonstrando dessa forma como pode acontecer em diferentes formatos além dos tradicionais.

Deste modo, o objetivo deste trabalho foi analisar as percepções sobre as experiências de utilização de metodologias ativas de ensino-aprendizagem por parte de graduandos e docentes do curso de Engenharia Civil da Universidade Federal de Santa Maria, RS. Através disso, pretende-se identificar as mudanças na aplicação dessas técnicas e nas estratégias pedagógicas adotadas no curso entre o formato presencial e o formato remoto, assim como as opiniões sobre sua contribuição no processo de aprendizagem e as dificuldades encontradas.

\section{Metodologias ativas de ensino-aprendizagem na engenharia}

As metodologias ativas de ensino-aprendizagem são importantes ferramentas de desenvolvimento de habilidades inter e intrapessoais e de senso crítico, que são muito bem avaliadas no mercado de trabalho por estarem associadas a profissionais com boa capacidade de gestão de projetos, solução de problemas, conduta ética e comunicação efetiva. A modernização do ensino mediante a aplicação dessas metodologias, juntamente com uma formação acadêmica bem embasada e a realização de atividades práticas em sala de aula, contribui expressivamente com o desenvolvimento dessas competências nos graduandos de engenharia (BARBOSA; MOURA, 2014; POURMAND; PUDASAINI; SHAHANDASHTI, 2021).

Assim, as metodologias ativas de ensino-aprendizagem mais utilizadas no âmbito dos cursos de engenharia focam no desenvolvimento de atitudes relacionadas à resolução de problemas e ao inter-relacionamento com outros profissionais. Várias são as opções encontradas na literatura especializada, as quais se amoldam a cada caso particular, de acordo com os objetivos da disciplina e os estilos de aprendizagem dos alunos (STEFANELLO et al., 2020). Esses estilos, identificados por Kolb (1984) como 
experimentação ativa, observação reflexiva, experiência concreta e conceitualização abstrata, estão ligados diretamente às preferências de aprendizado dos alunos por estímulos de fazer, ver, sentir e pensar, respectivamente, aos quais as atividades planejadas em sala de aula precisam se adaptar (KURI, 2004).

No âmbito da engenharia destacam-se por sua aplicação as seguintes metodologias ativas de ensino-aprendizagem:

\section{Project Based Learning}

A Aprendizagem Baseada em Projetos (ou Project Based Learning - PBL) é uma metodologia ativa que possui grande compatibilidade com as disciplinas nos cursos de engenharia, fundamentando-se na elaboração de projetos, relatórios ou estudos de caso relevantes e conexos com o mundo real. Devido à abordagem prática do método, o estudante acaba solucionando problemas e desenvolvendo um raciocínio crítico e um conhecimento muito mais amplo e completo sobre os assuntos teóricos abordados em sala de aula. Além disso, a PBL desenvolve competências ímpares e essenciais para o engenheiro, de forma conjunta ao conhecimento técnico (GUO et al., 2020; KRAJCIK; SHIN, 2014; RICAURTE; VILORIA, 2020; SHARMA et al., 2020)

\section{Team Based Learning}

A Aprendizagem Baseada em Equipes (ou Team Based Learning - TBL) é outra metodologia de grande aplicação nas instituições de ensino superior. Ela conta com a formação de equipes de determinado número de alunos para o desenvolvimento das atividades acadêmicas. Logo, é um método de muito fácil aplicação, mas que demanda uma boa interação entre os envolvidos para a efetividade da aprendizagem. Além disso, a TBL desenvolve capacidades de adaptação, comunicação e gestão de pessoas nos graduandos, vistas como necessárias nos profissionais engenheiros pelos seus empregadores, tornando indispensável sua aplicação ainda na graduação (COHEN; ROBINSON, 2018; LUCIANO; ALVES; LIMA, 2018; NAJDANOVIC-VISAK, 2017; OLIVEIRA et al., 2018).

\section{Sala de Aula Invertida}

Outra metodologia ativa bastante conhecida é a chamada sala de aula invertida, que, como o nome indica, propõe uma mudança na dinâmica do ambiente de ensino, através da interação prévia do estudante sobre o assunto tratado, de forma a gerar em sala de aula maiores questionamentos ao professor e uma aprendizagem mais aprofundada e sustentada. Esse método acaba por minimizar a ocorrência de exposições com conteúdo muito teórico, vistas pelos estudantes como pouco atrativas, além de desenvolver habilidades de comunicação. Ainda, vale ressaltar que a sala de aula invertida apresenta uma maior potencialidade atualmente em virtude da ampla quantidade de informações disponível na internet e mediante ferramentas informáticas (LUCIANO; ALVES; LIMA, 2018; POURMAND; PUDASAINI; SHAHANDASHTI, 2021; SERGIS et al., 2018; ZAPPE et al., 2009).

\section{Gamificação}

A metodologia ativa Game Based Learning (ou Gamificação) se baseia na aplicação de jogos em sala de aula de forma educativa e informativa aos estudantes. Esses jogos podem ser de cartas ou de tabuleiro, aplicados no quadro negro ou ainda, os mais comuns atualmente, de forma digital pelos celulares ou computadores dos alunos. Através da introdução de elementos lúdicos no processo de ensinoaprendizagem, a gamificação envolve o estudante de forma emocional, 
desenvolvendo nele responsabilidade por suas ações e seus julgamentos e gerando um crescimento de habilidades de solução de problemas, muito importante aos engenheiros. Essa metodologia vem ganhando espaço devido ao interesse promovido entre os alunos por meio das disputas e competições e das recompensas que podem ser atribuídas a um bom desempenho dos graduandos (ALANNE, 2016; BODNAR; CLARK, 2017; DESHPANDE; HUANG, 2011; VENTURA, 2021).

\section{Avaliação entre Pares}

Finalmente, a avaliação entre pares é uma metodologia ativa que foca no processo avaliativo, de forma a acrescentar, junto à opinião do professor, o ponto de vista dos alunos na mensuração do desempenho dos próprios colegas. Dessa forma, se gera um processo de avaliação mais completo, assim como uma realimentação da aprendizagem do estudante, a partir da possibilidade dos feedbacks entre ele e o professor. Além disso, evidencia-se que essa metodologia não traz perdas se aplicada de forma remota ou em turmas de grande ou de pequeno número de alunos. Percebese também que, além da notória contribuição à aprendizagem do graduando, este método facilita todo o processo de avaliação realizado pelos professores, podendo ser um forte aliado para eles nesses momentos (CHENG et al., 2014; COSTA, 2017; SUN et al., 2015).

\section{Metodologia}

O desenvolvimento do presente trabalho focou-se na análise das metodologias ativas de ensino-aprendizagem no curso de Engenharia Civil da Universidade Federal de Santa Maria (UFSM). Para isso, a partir de estudo conceitual e bibliográfico do assunto, elaborou-se um questionário na plataforma Google Forms para obtenção da opinião anônima dos estudantes do curso e, da mesma forma, organizou-se um roteiro com questionamentos para realização de entrevistas síncronas através da ferramenta de videoconferência Google Meet com os professores do curso, de forma a colher sua opinião sobre o objetivo da pesquisa e também sobre as alterações sofridas pela suspensão das atividades presenciais na Universidade.

As entrevistas com os professores aconteceram efetivamente entre os meses de outubro e novembro de 2020, após a realização de entrevistas piloto com alguns docentes próximos aos autores da pesquisa, para a sondagem dos possíveis pontos de melhoria para as perguntas elaboradas. Uma vez definido o roteiro definitivo, entrou-se em contato com cada professor e marcou-se um horário de sua preferência para a entrevista. Os assuntos abordados nas entrevistas buscavam compreender a familiaridade do docente com as metodologias ativas, além dos métodos utilizados por ele para ministrar suas disciplinas, tanto na parte teórica quanto na prática do conteúdo. Ainda procurou-se conhecer quais as dificuldades encontradas pelo professor na aplicação das metodologias ativas, juntamente com as mudanças realizadas por ele para o bom andamento das aulas de forma remota, devido à adaptação necessária durante a pandemia enfrentada atualmente.

O tratamento do grande número de dados obtidos nas entrevistas, a maioria deles mais discursivos, fez-se de forma qualitativa a partir da transcrição das respostas dadas pelos professores durante sua fala. Além disso, para uma melhor ilustração desses resultados, foram criadas nuvens de palavras para alguns tópicos de discussão, entre eles as formas de avaliação aplicadas, os recursos didáticos utilizados e as dificuldades encontradas para implementação das metodologias ativas 
nas aulas em formato presencial e remoto. Essas nuvens de palavras foram construídas no site gratuito www.wordclouds.com. Antes de iniciar o processo foram selecionados os textos de todas as respostas obtidas nas entrevistas para a pergunta escolhida e efetuou-se o tratamento deles, deixando apenas substantivos, adjetivos e verbos no infinitivo, com o objetivo de captar de forma mais adequada os termos relacionados. Dessa forma, foi possível importar o arquivo de texto no site, conferir a lista de palavras e o número de vezes que cada uma apareceu e configurar o design da imagem da nuvem resultante. Esse processo foi realizado para cada uma das nuvens de palavras que aparecem no corpo deste trabalho.

Por outro lado, o questionário aplicado aos alunos do curso também passou por um processo de teste inicial, com aplicação em formato piloto com outros estudantes de Engenharia Civil integrantes do grupo de pesquisa onde se desenvolveu este trabalho, o que trouxe diversas melhorias ao questionário aplicado efetivamente aos alunos na sequência. A divulgação do formulário foi feita por meio de e-mails enviados pela coordenação do curso a todos os matriculados, e foi sendo reforçada através de lembretes enviados aos grupos de WhatsApp das turmas de todos os semestres do curso, de forma a possibilitar uma boa participação dos graduandos no estudo.

O formulário foi composto por várias seções, com o intuito de permitir aos alunos expressarem sua opinião sobre os objetivos da pesquisa de forma clara e direta. Dentre as questões abordadas, as iniciais buscaram caracterizar o estudante e o seu estilo de aprendizagem, além da sua concordância, após uma breve explanação do assunto, sobre a utilização das metodologias ativas nas disciplinas do curso. Nas seguintes seções incluíram-se questões diretamente voltadas àquelas metodologias ativas mais frequentemente utilizadas nas engenharias segundo a pesquisa bibliográfica realizada: PBL, TBL, sala de aula invertida, gamificação e avaliação entre pares. Nessa parte, os estudantes puderam ainda deixar sua opinião sobre a experiência vivida com cada um desses métodos e os principais obstáculos encontrados.

O formulário ficou disponível aos estudantes durante todo o mês de novembro de 2020, possibilitando ampla coleta de respostas. Estes dados foram apurados através de estatística básica, cruzamentos de dados e com a realização de gráficos, através da ferramenta tabela dinâmica no software Microsoft Excel, e relacionados com os resultados obtidos das entrevistas com os professores e discutidos de acordo com a literatura especializada.

\section{Resultados e discussão}

O curso de Engenharia Civil da Universidade Federal de Santa Maria contava com um total de 386 alunos matriculados regularmente no segundo semestre de 2020, conforme consta no portal da UFSM (UFSM, 2020). Todos eles receberam convite para responder o questionário elaborado, e no total obteve-se 82 respostas dos discentes do curso, resultando em uma taxa de resposta de $21,2 \%$, superando a amostragem mínima de 78 participantes projetada com $95 \%$ de grau de confiança e $10 \%$ de erro amostral, e abrangendo respondentes de todos os semestres do curso. Dessa forma, o erro amostral obtido foi de $9,62 \%$.

Como resultados da caracterização dos alunos participantes da pesquisa, a distribuição por idade indica que a maioria deles se encontra na faixa etária compreendida entre 19 e 22 anos, que corresponde às idades habituais ao ingresso 
na Universidade após a conclusão do ensino médio. No entanto, existe uma parcela significativa de acadêmicos com idades entre 23 e 25 anos, correspondente a graduandos que ingressaram mais tarde no curso ou que estão demorando mais do que o tempo mínimo estabelecido de 10 semestres, o que, devido à complexidade do curso ou escolhas de organização de carga horária, é relativamente frequente. Percebe-se, também, a inclusão de estudantes com idades acima de 30 anos efetuando o curso, talvez objetivando a profissionalização.

No que diz respeito ao gênero, constata-se uma distribuição praticamente igualitária, tendo em vista que os estudantes do sexo masculino correspondem a $53,8 \%$ e do sexo feminino a 46,3\%. É importante ressaltar que, tradicionalmente, os cursos de engenharia têm uma preeminência de alunos de sexo masculino, aspecto que paulatinamente vai desaparecendo como resultado do maior envolvimento da mulher em todas as áreas de atuação, sem atender a costumes já enraizados pela sociedade (STEFANELLO et al., 2020).

Em relação à acessibilidade dos alunos a aparelhos eletrônicos e a internet, as respostas dos entrevistados revelam que $98 \%$ deles possuem ambos os recursos em casa, sendo que apenas $1 \%$ informou não possuir computador e utilizar apenas 0 celular, enquanto outro 1\% utiliza computadores emprestados. A Figura 1 apresenta os resultados em relação ao número de horas semanais destinadas à utilização de computadores. Percebe-se que os alunos prioritariamente utilizam os computadores por mais de 40 horas semanais. É preciso considerar também que a parcela de respondentes que utilizam por mais de 20 horas é bastante significativa, próxima ao $90 \%$, provavelmente pela exigência das aulas virtuais e realização de atividades diretamente no computador.

Figura 1 - Utilização semanal do computador por parte dos alunos

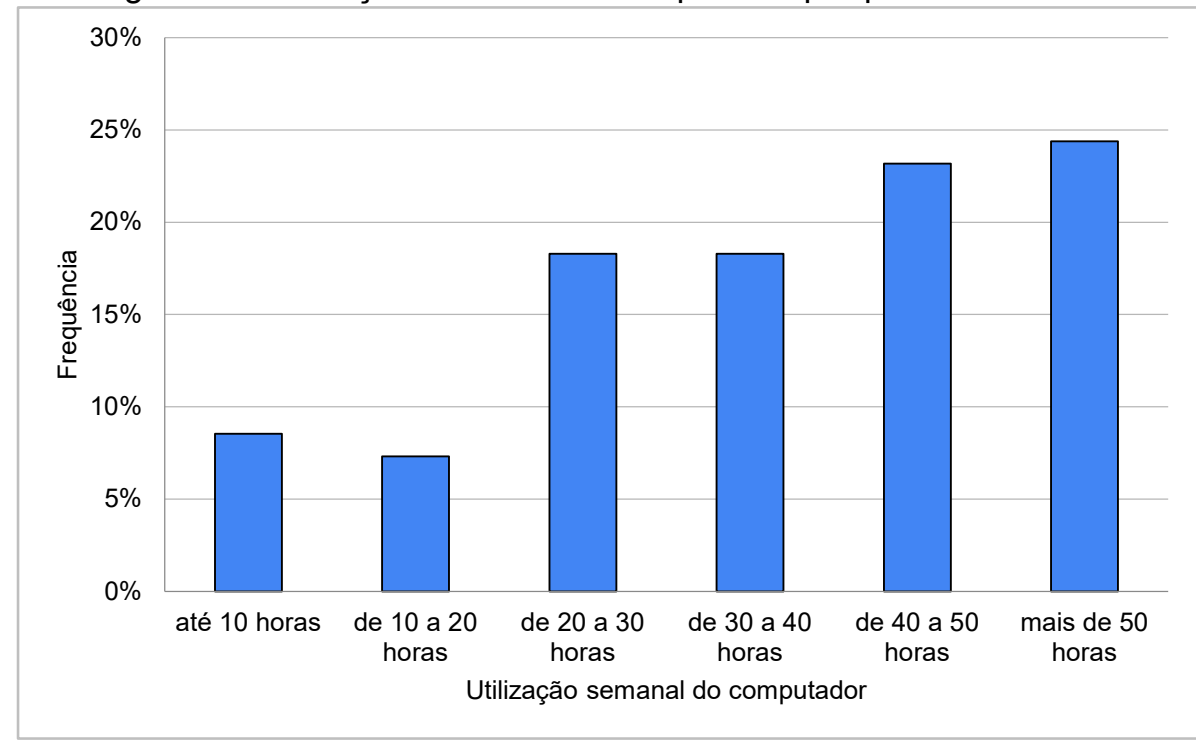

Fonte: os autores.

Esses dados são destacáveis especialmente nesse momento de ensino remoto, para o qual mostra-se indispensável o uso de computador com acesso à internet, embora também são de grande importância no ensino presencial (COSTA, 2020). Quando comparados com resultados obtidos por Stefanello et al. (2020) em um contexto similar, porém anterior à suspensão das atividades presenciais devido à pandemia, percebe-se uma mudança muito evidente no aumento da utilização dos 
computadores, praticamente dobrando o número médio de horas de uso desses aparelhos, o que, de certa forma, também é preocupante.

Realizou-se também uma análise sobre o estilo de aprendizagem reportado pelos alunos, e $65 \%$ deles afirmaram ter preferência pela experimentação ativa, estilo no qual o aluno aprende efetivamente na prática. Notou-se igualmente que outras formas de aprendizagem escolhidas pelos alunos foram menos expressivas, aparecendo em segundo lugar a observação reflexiva (16\%). Esta forma de aprendizado fundamentalmente advém do ver e escutar, ou seja, mediante a experiência concreta, que necessita uma relação emocional ao assunto por parte do aluno (KOLB, 1984; KURI, 2004). Esta preferência de estilo de aprendizado é característica dos cursos de engenharia e outras áreas aplicadas, como exposto por Stefanello et al. (2020), em cujo estudo os autores obtiveram valores muito similares, mesmo se tratando de uma situação em que o processo de ensino-aprendizagem ocorria de forma presencial.

$\mathrm{Na}$ Figura 2 percebe-se essa maior aquisição de conhecimento através de experimentação ativa dos estudantes, de ambos os sexos, mas evidencia algumas diferenças. Assim, o segundo estilo de aprendizagem mais mencionado pelo sexo masculino é a experiência concreta, que visa um envolvimento mais emocional do aluno, sendo esse estilo praticamente não citado pelas mulheres. Porém, a observação reflexiva, voltada a uma metodologia mais tradicional, é mais assinalada pelo sexo feminino, mas ainda aparece no sexo masculino. A conceitualização abstrata ainda é referida pelos dois sexos, mesmo que menos presente.

Figura 2 - Estilos de aprendizado dos alunos segundo gênero

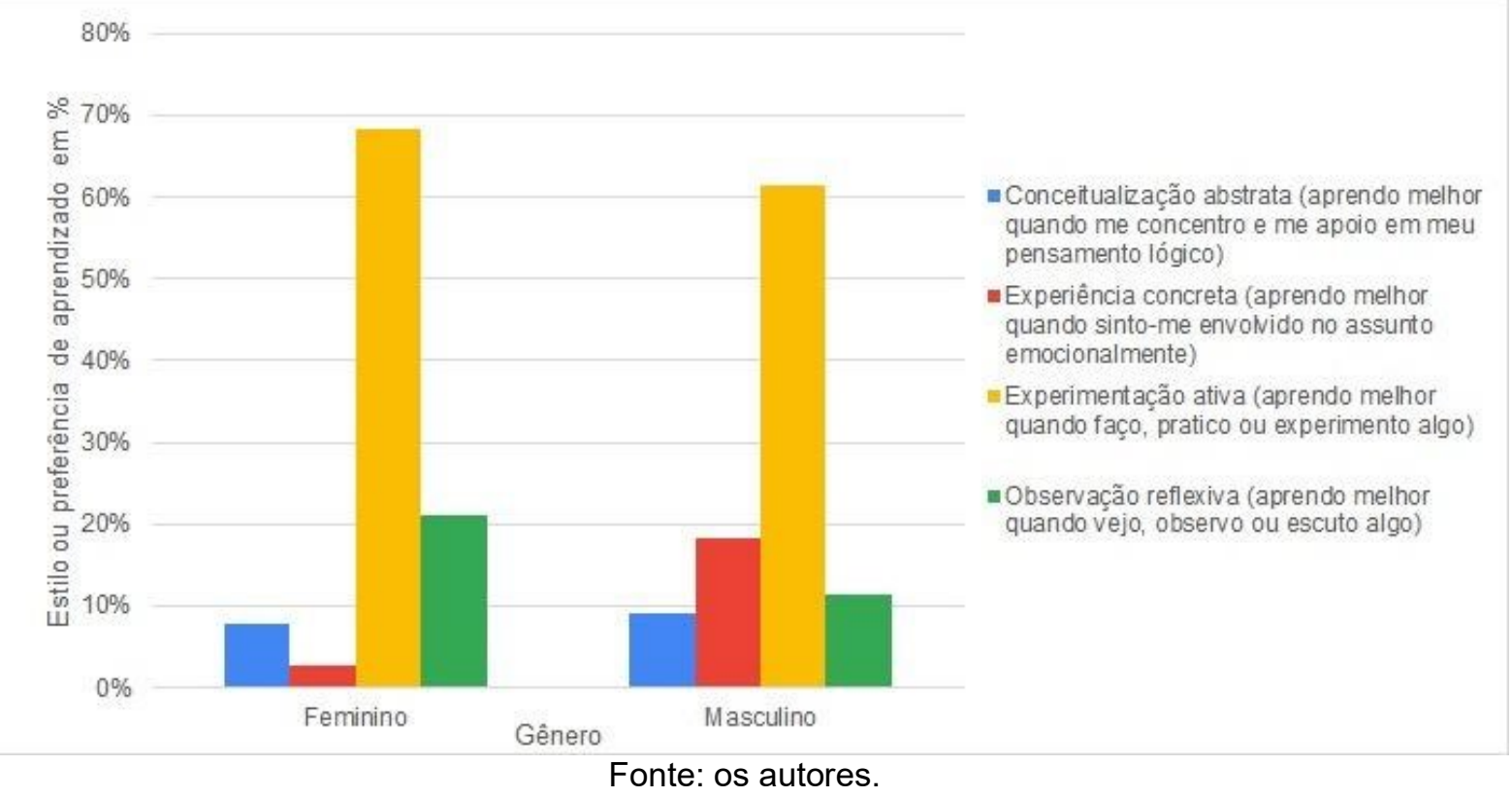

Também foi questionado aos alunos sobre seu grau de concordância em relação ao uso de metodologias ativas nas disciplinas do curso de Engenharia Civil. Os resultados mostraram que a maior parte do corpo discente aprova a sua utilização, alcançando um total de $97 \%$ de concordância total ou parcial. Apenas $2 \%$ dos respondentes não concordam e nem discordam de seu uso e 1\% expressaram sua discordância parcial à sua utilização, um valor realmente muito pequeno, sendo a discordância total nula. Esses resultados mostram a predisposição dos alunos ao uso de metodologias ativas nas disciplinas, procurando ambientes de ensino- 
aprendizagem mais participativos e práticos, condizentes com o caráter técnico dos cursos de engenharia e com a preferência de estilo de aprendizado manifestado.

Dentro desses resultados gerais, na Figura 3 constata-se algumas diferenças segundo gênero, idade e tempo no curso. Assim, percebe-se uma maior concordância das alunas e de estudantes mais jovens com o uso das metodologias ativas, enquanto se identifica uma discordância relativamente maior por parte dos alunos de 24 anos ou mais. Ainda observando a Figura 3, é notável que a grande maioria dos alunos, independente do semestre em que se encontra, concorda fortemente, ou parcialmente com o uso das metodologias ativas. Além disso, há uma maior concordância dos alunos que já superaram a primeira metade do curso, momento em que entram em contato com disciplinas mais específicas e práticas dentro das áreas do curso e, portanto, com um uso mais aplicado das metodologias ativas nas matérias (NAJDANOVIC-VISAK, 2017). Porém, apenas quem está no início do curso, onde ainda se realizam cadeiras básicas de todas as engenharias, indicou discordar parcialmente de seu uso.

Figura 3 - Grau de concordância dos alunos sobre o uso de metodologias ativas

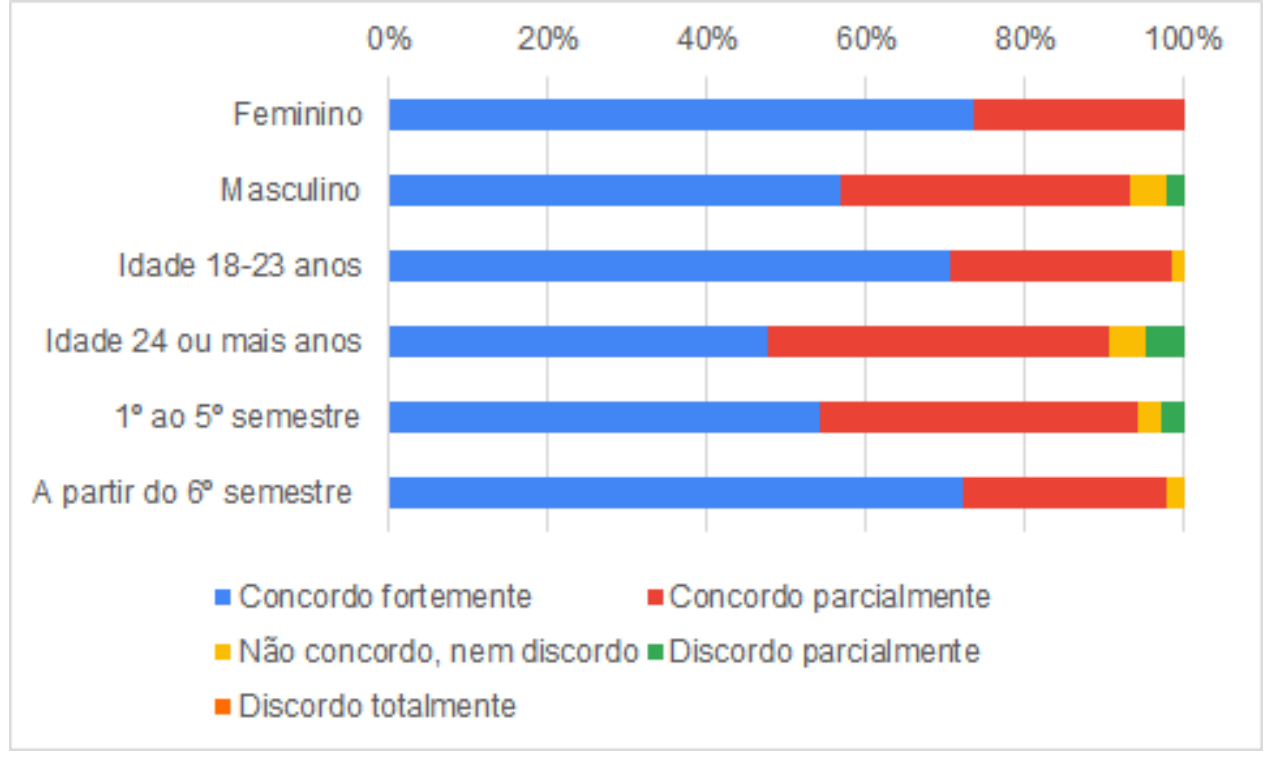

Fonte: os autores.

Em relação às entrevistas realizadas com os professores, 42 deles participaram, compreendendo um total de 45 disciplinas da estrutura curricular do curso vinculadas a 9 departamentos, sendo os seguintes: Estruturas e Construção Civil, Transportes, Engenharia de Produção e Sistemas, Engenharia Sanitária e Ambiental, Expressão Gráfica, Física, Matemática, Química e Direito.

Com o apoio da ferramenta de criação de nuvem de palavras a partir das respostas discursivas dos professores sobre o questionamento que solicitava o que entendiam por metodologia ativa de ensino-aprendizagem, obteve-se um resultado bastante amplo e representativo. Na Figura 4 é possível perceber que as palavras de maior destaque trazem o aluno como responsável pela busca do seu conhecimento e como protagonista do processo de ensino-aprendizagem. Destacam-se também palavras como "participação/participar", "responsabilidade", "aplicação", "prática", "desenvolver", "aprender" e "construir", reforçando o sentido da escolha e iniciativa do aluno para concretização do aprendizado, de forma ativa. Outras palavras que chamam a atenção são algumas que se relacionam a metodologias específicas, como "estudo de caso", "competição", "projeto", "problema" e "autodidata", fazendo 
referência a experiências de PBL, gamificação ou sala de aula invertida. Esses resultados reforçam o entendimento existente entre o corpo docente do curso sobre as metodologias ativas de ensino-aprendizagem e das opções mais comumente aplicadas na área das engenharias.

Figura 4 - Nuvem de palavras a partir das respostas dos professores sobre a questão "O que entende por metodologias ativas de ensino-aprendizagem?"

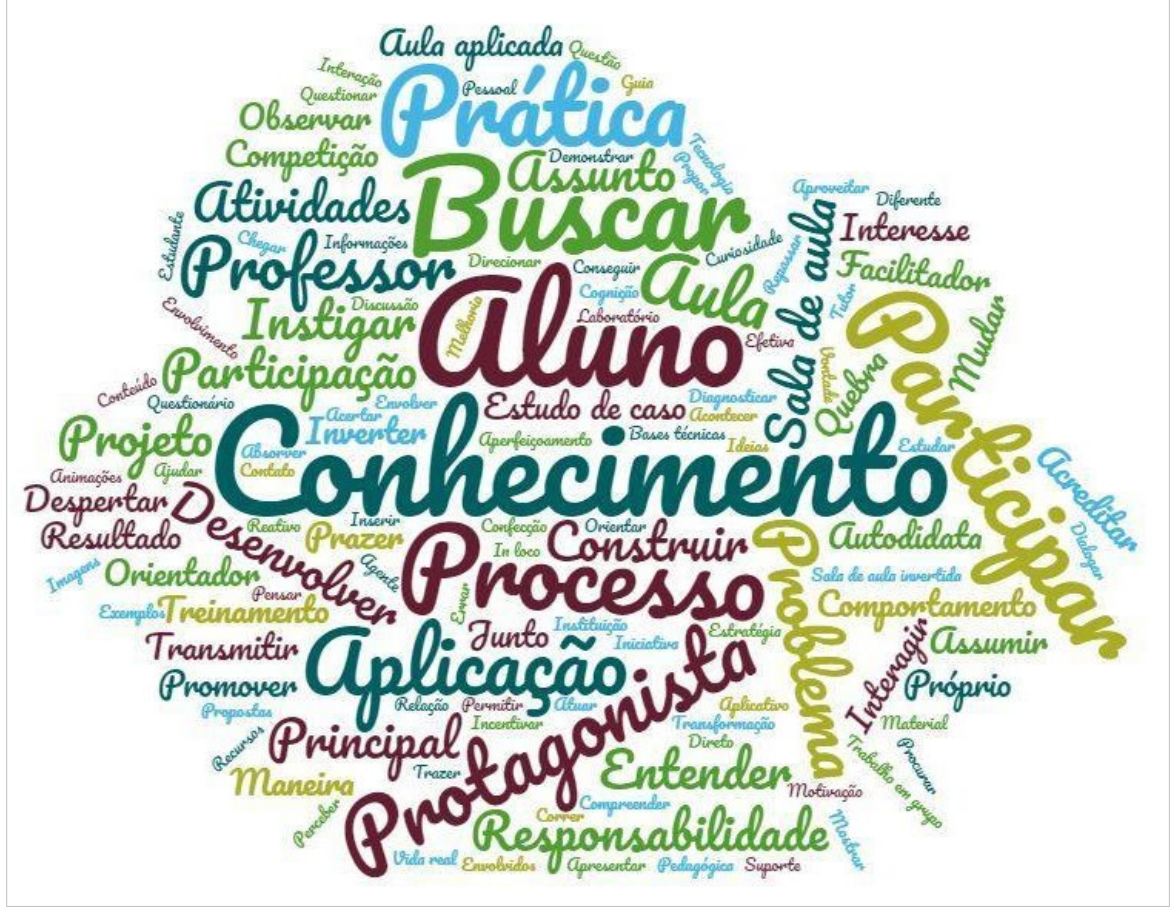

Fonte: os autores.

Um ponto abordado nas entrevistas com os professores foi a indicação das metodologias ativas utilizadas por eles para o exercício de suas aulas. Na Figura 5 é possível identificar que uma boa parte dos professores relatou o uso dessas técnicas, sendo a metodologia Team Based Learning a mais mencionada, seguida pelo Project Based Learning. Ambas metodologias são as que apresentam maior utilização na área de engenharia, como indicado por Barbosa e Moura (2014) e Sharma et al. (2020), procurando o desenvolvimento de atitudes de trabalho em equipe, resolução de problemas e elaboração de documentos técnico-científicos. 
Figura 5 - Metodologias ativas de ensino-aprendizagem aplicadas pelos docentes

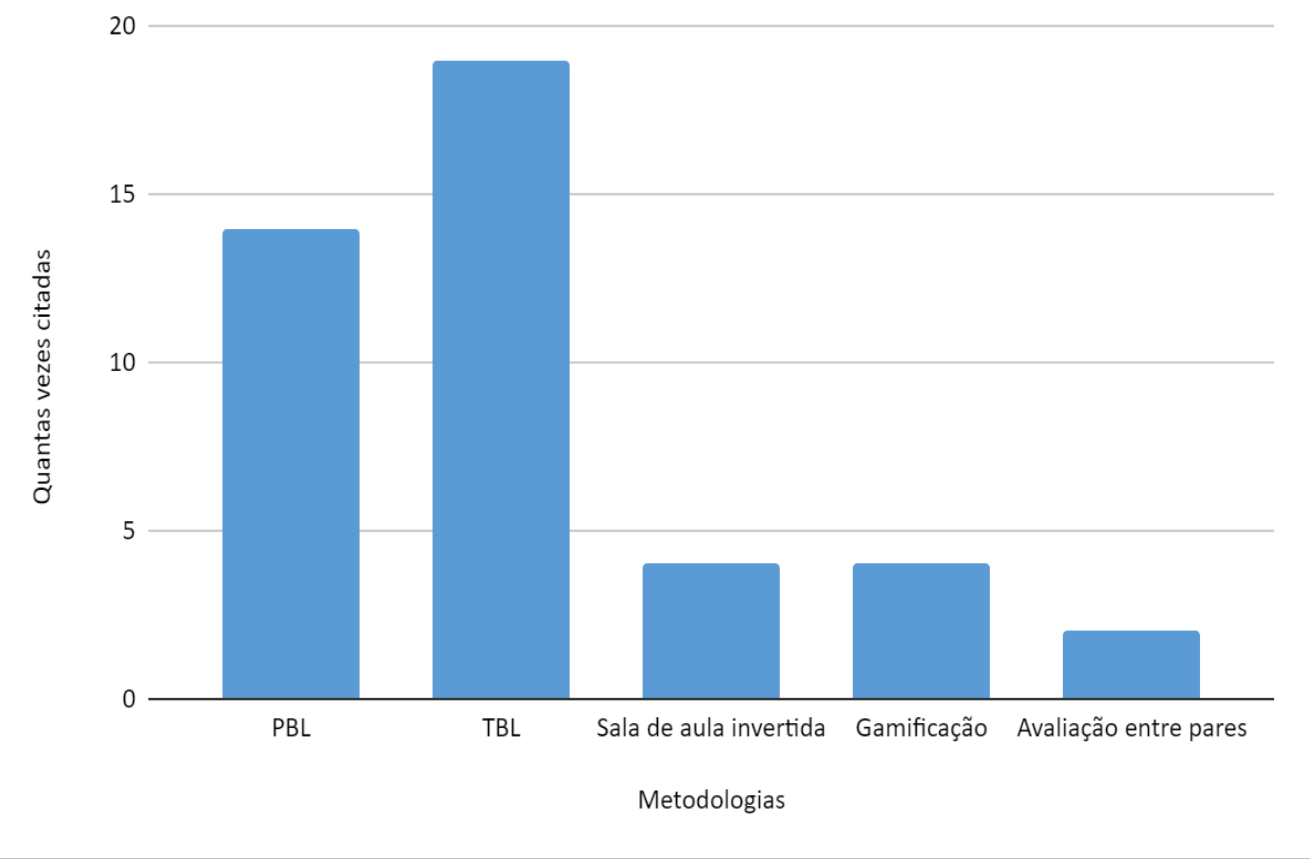

Fonte: os autores.

Em relação às opiniões dos estudantes do curso sobre essas duas metodologias ativas mais utilizadas nas disciplinas, é importante destacar que a imensa maioria deles (mais do 60\%) aprova sua utilização, indicando uma grande ou muito grande colaboração delas com a aprendizagem. Segundo esse resultado, os alunos podem se mostrar mais receptivos e participativos quando as metodologias TBL e PBL são aplicadas em sala de aula, facilitando o planejamento por parte do docente.

Na Figura 6 apresenta-se a relação entre as opiniões dos alunos sobre o desempenho das metodologias PBL e TBL no curso e nela é possível perceber que os alunos que expressaram que a metodologia TBL colabora muito fortemente com o aprendizado também se posicionaram assim para a metodologia PBL. Dessa forma, parece claro que a combinação de ambas metodologias nas disciplinas do curso de Engenharia Civil é benéfica para os alunos. Por outro lado, as opiniões dos alunos de que PBL e TBL contribuem "pouco" ou "muito pouco" com sua aprendizagem são pequenas e coincidentes para ambas técnicas, o que pode indicar uma rejeição sistemática pelo uso de metodologias ativas, aspecto que deve ser identificado pelos docentes para tentar melhorar a experiência desses alunos e integrá-los adequadamente nas equipes e projetos (NAJDANOVIC-VISAK, 2017). 
Figura 6 - Relação entre opiniões dos alunos sobre colaboração das metodologias PBL e TBL na aprendizagem

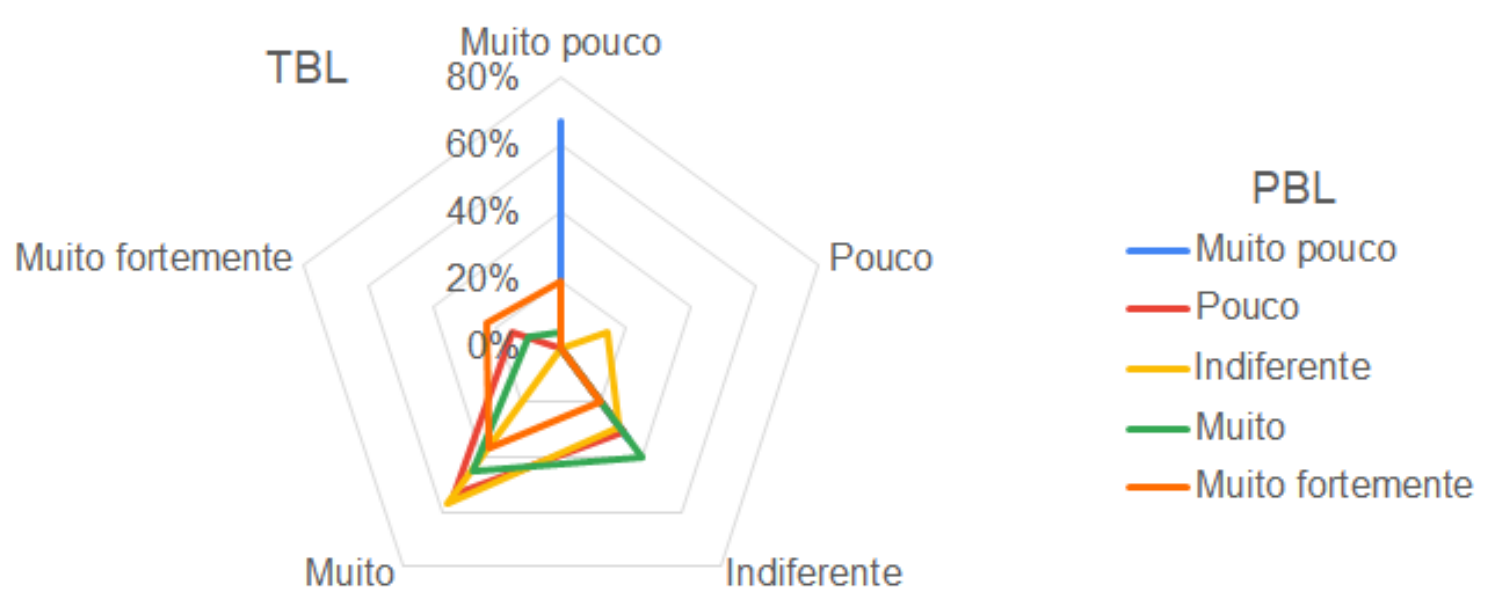

Fonte: os autores.

Aprofundando os resultados obtidos das questões apresentadas aos alunos sobre sua opinião com a realização de trabalhos em grupo, chama a atenção que $21 \%$ deles se manifestam moderadamente contrários à utilização da técnica TBL nas disciplinas, evidenciando que determinados alunos se sentem prejudicados ao realizarem esse tipo de atividade, o que realmente pode se configurar como um defeito na aplicação da metodologia ou um problema de socialização, pois o exercício da engenharia exige o trabalho em equipes, muitas vezes interdisciplinares. Portanto, esse é um aspecto que deve ser explorado com maior detalhe nos programas pedagógicos do curso e no planejamento das atividades nas disciplinas ao longo dos semestres e das diferentes áreas de conhecimento.

Ao relacionar essas opiniões dos alunos sobre a metodologia TBL com o número ideal de integrantes para esses grupos, obtém-se o gráfico apresentado na Figura 7, que mostra que os alunos que concordam altamente com a metodologia TBL, maioritariamente acreditam que o número ideal de alunos para trabalhos em equipe seja de 4 a 5 pessoas. Em relação aos que se consideram moderadamente a favor do uso de TBL, pensam que o melhor número de pessoas para um grupo esteja entre 3 e 4 pessoas. No entanto, os que se manifestam contrários ao uso do TBL em sala de aula mostram a maior percentagem de opinião sobre realização de trabalhos apenas em duplas, ou ainda sozinhos, embora em baixa percentagem em relação ao total dos alunos. Essas opiniões reforçam as percepções anteriores sobre os resultados de aplicação da metodologia. 
Figura 7 - Opinião dos alunos sobre realização de trabalhos em grupo nas disciplinas e número de integrantes ideal para esses grupos

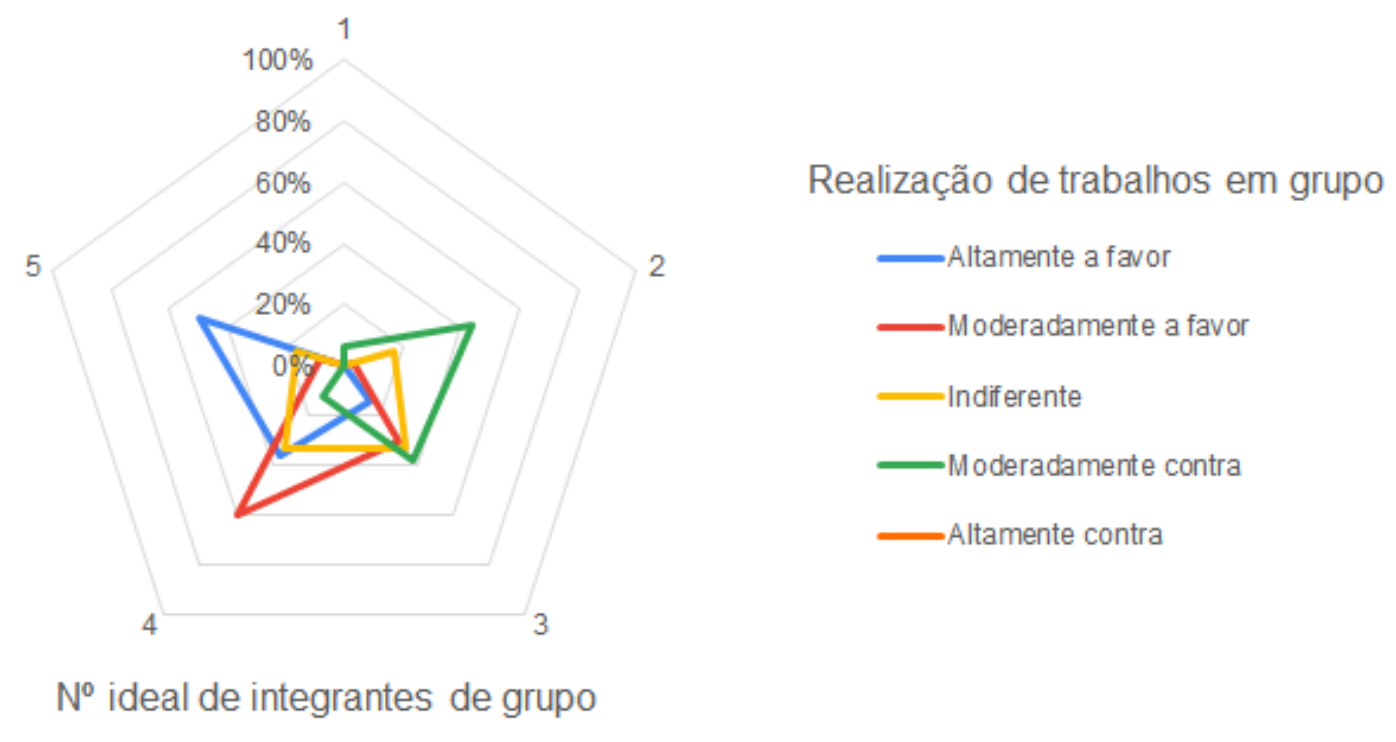

Fonte: os autores.

Como se observa na Figura 5, as metodologias de sala de aula invertida, gamificação e avaliação entre pares também estão presentes nas disciplinas do curso de Engenharia Civil da UFSM, mas com menor destaque por parte dos professores. Os alunos também foram questionados sobre seu ponto de vista em relação à capacidade dessas técnicas para fornecer conhecimento e os resultados estão resumidos na Figura 8.

Assim, no caso da gamificação e sala de aula invertida, pode-se verificar que boa parte das respostas se manteve entre os números mais elevados da escala de concordância, indicando que a maior parte dos alunos julga de maneira favorável sua utilização, destacando-se a gamificação sobre as outras duas. Além disso, também é possível perceber uma frequência expressiva das notas mais baixas na escala de concordância, sobretudo no caso da metodologia da avaliação entre pares, o que indica que muitos alunos não identificaram a utilização dessa técnica como produtiva à aprendizagem e/ou não gostaram da experiência desafiadora de avaliar os colegas ou de serem avaliados por eles. No caso da sala de aula invertida, essa opinião dos alunos pode estar relacionada a uma compreensão de que estariam aprendendo sozinhos, e assim sentem que não teriam tanto apoio dos professores, o que levaria a uma falha no seu ensino, ou talvez pelo inadequado planejamento e/ou desenvolvimento da estratégia nas disciplinas.

A partir desses resultados, pensando na inserção dos novos profissionais formados no mercado de trabalho, essa atitude negativa em relação a algumas das metodologias analisadas deve ser trabalhada de uma melhor maneira durante o curso, pois serão habituais as situações em que, dentro de uma empresa ou organização, além de trabalhar em equipe, existirá a necessidade de procurar informações por conta própria e de avaliar ou receber críticas por parte de outros colegas de profissão. Um baixo desempenho dos futuros engenheiros nesses quesitos avaliados pode levar a conflitos internos nas equipes de trabalho ou desmotivação nas responsabilidades recebidas, prejudicando a organização no seu conjunto, o que destaca a necessidade 
dos docentes de aprimorarem ainda mais essas atitudes com um adequado planejamento, execução e explicação das iniciativas.

Figura 8 - Opinião dos alunos quanto à colaboração das metodologias Gamificação, Sala de Aula Invertida e Avaliação entre Pares na aprendizagem

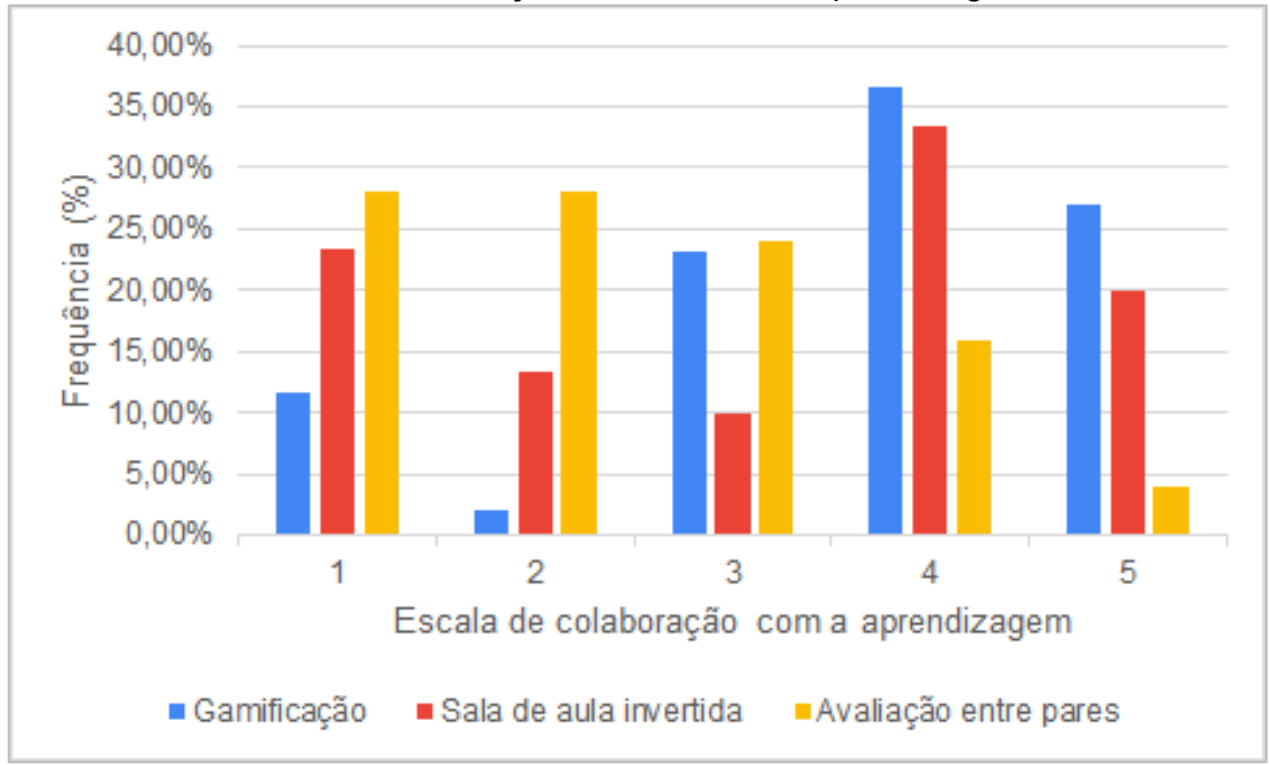

Fonte: os autores.

Nesse sentido, cabe analisar as dificuldades que os professores enfrentaram para aplicar as metodologias ativas nas disciplinas do curso, tanto no formato presencial quanto no formato remoto, a partir das respostas obtidas nas entrevistas. Assim, com o apoio das nuvens de palavras geradas e apresentadas na Figura 9, é perceptível que houve grandes mudanças e surgiram novos desafios para os docentes, como outros estudos têm reportado (COSTA, 2020; KOLHEKAR; SHAH; JADJAV, 2021).

Figura 9 - Nuvens de palavras a partir das respostas dos professores sobre a questão "Quais dificuldades encontra na implementação das metodologias ativas de ensino-aprendizagem?". (a) Formato presencial. (b) Formato remoto

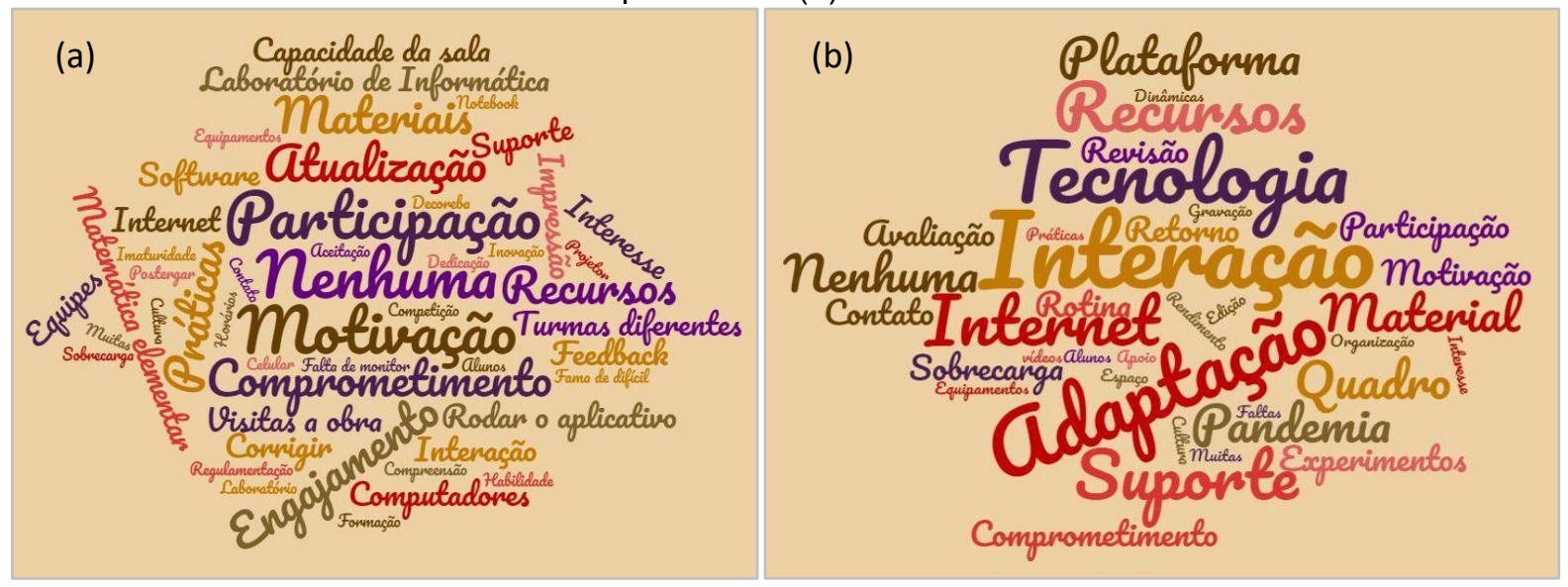

Fonte: os autores.

Quando questionados sobre as dificuldades em aplicar as metodologias ativas em formato presencial (Figura 9(a)), nota-se que muitos professores não perceberam dificuldades, pois aparece destacada na nuvem obtida a partir desse questionamento a palavra "nenhuma", entretanto, possuem protagonismo também palavras como "participação", "motivação", "comprometimento" e "engajamento". Logo, verifica-se que o comportamento e disposição dos alunos influencia muito na percepção do 
professor sobre as atividades, dificultando a implantação de metodologias ativas quando não há um retorno positivo da classe. Percebe-se também que a infraestrutura é um dos pontos principais de dificuldade para com a aplicação de certas metodologias, visto a ilustração de palavras como "capacidade da sala", "laboratório de informática", "recursos", "materiais" e "computadores". Fica evidente assim a necessidade de utilização de equipamentos de informática para as atividades planejadas, em quantidade suficiente para as turmas. Outro termo que ganha destaque é "atualização", o que também indica a necessidade dos docentes de manterem um contínuo aprendizado e aprimoramento do conhecimento, interpretado tanto desde o ponto de vista técnico como pedagógico para aplicação das metodologias ativas (IGLESIAS-PRADAS et al., 2021; SANTIAGO et al., 2021).

Já na nuvem de palavras referente às dificuldades de aplicação das metodologias ativas em formato remoto (Figura 9(b)), o comportamento dos alunos continua sendo uma questão chave, mas dessa vez destacado com a palavra "interação". Com a implementação das aulas virtuais ou até mesmo gravadas nesse novo formato, notase um grande distanciamento entre alunos e professores, e a falta de retorno e de participação por parte dos alunos tem sido um apontamento negativo frequente dos docentes (COSTA, 2020; JEONG et al., 2019). Além dela, outras palavras que aparecem em destaque são "adaptação", "tecnologia", "recursos", "plataforma" e "suporte", que evidenciam que pode ter havido dificuldade de adaptação aos meios tecnológicos e/ou falta de suporte técnico para o desenvolvimento das atividades. Nessa segunda nuvem a palavra "nenhuma" ainda aparece, porém dessa vez com menos destaque do que na anterior, o que demonstra que uma parcela menor dos professores se sentia preparado ou apto para a implantação das metodologias ativas em formato remoto sem dificuldades.

Outro dos aspectos capitais nas disciplinas e diretamente relacionados com a aplicação de metodologias ativas de ensino-aprendizagem é a estratégia de avaliação dos alunos. Com objetivo de captar as diferenças surgidas com a modificação de relacionamento entre professores e alunos imposto pela pandemia, se solicitou aos docentes que relacionassem as ferramentas de avaliação aplicadas nas disciplinas que ministram no formato presencial e remoto. A partir das suas respostas, foram também criadas nuvens de palavras, apresentadas na Figura 10, na qual pode-se perceber que não houve grandes alterações nas estratégias principais adotadas com esse objetivo, que são: provas, projetos, apresentação de trabalhos, seminários e exercícios. Entretanto, as condições e o ambiente mudaram e, dessa forma, no formato remoto essas avaliações, mesmo que consideradas as mesmas, possuem algumas diferenças na aplicação, como a consulta ao material ou até mesmo a colaboração entre os colegas em alguns casos (IGLESIAS-PRADAS et al., 2021). Essa associação de alunos para discussão de problemas e desafios pode ser uma inovação bastante interessante, já que simula o que possivelmente acontecerá no ambiente de trabalho.

(1)


Figura 10 - Nuvens de palavras a partir das respostas dos professores sobre a questão "Quais estratégias de avaliação utiliza nas suas disciplinas?". (a) Formato presencial. (b) Formato remoto

(a)

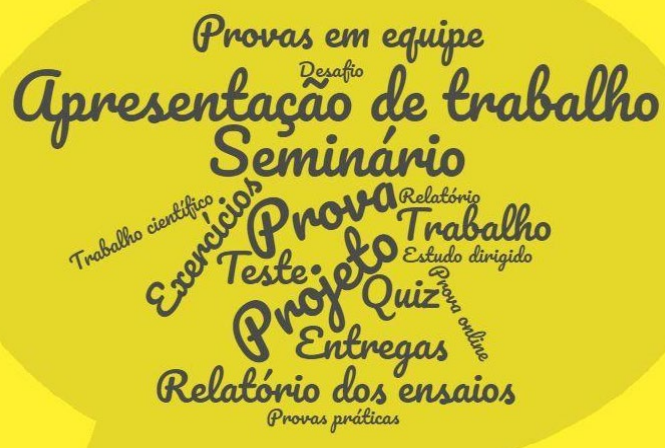

(b)

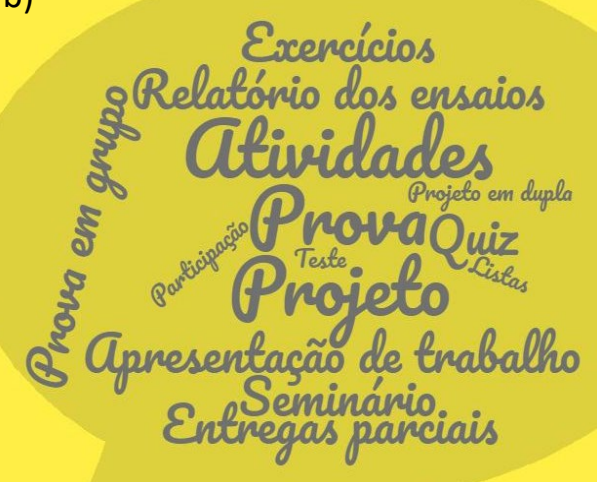

Fonte: os autores.

Finalmente, as entrevistas com os professores obtiveram dados sobre os recursos didáticos usados para as aulas em formato presencial, tanto para a parte teórica quanto para a parte prática, assim como no formato remoto atual. $\mathrm{Na}$ comparação entre as nuvens de palavras geradas a partir das respostas a estes questionamentos (Figura 11) é possível notar uma considerável diferença: com a suspensão das atividades presenciais, ganham especial protagonismo nas salas de aula virtuais vários recursos informáticos com apoio de internet, como o Google meet, WhatsApp e e-mail. Confrontando essas palavras destacadas com as que aparecem na nuvem relativa aos recursos para as aulas teóricas presenciais, fica evidente que os conteúdos deixaram de ser explanados no quadro e registrados em apostilas, e se tornaram vídeos no Youtube, arquivos pdf e slides para estudo, disponibilizados no Moodle ou Google Classroom, como outros autores têm reportado (COSTA, 2020). As aulas práticas, em laboratório e até mesmo as visitas técnicas que aconteciam no formato presencial ficaram inviabilizadas no ambiente virtual e a solução encontrada foi também a gravação de vídeos demonstrativos ou transmitidas com apoio de simuladores.

Pela análise comparativa realizada, percebe-se que os meios tecnológicos se tornaram indispensáveis para a continuidade das atividades acadêmicas no formato remoto e os recursos utilizados nas atividades presenciais tiveram que ser adaptados para viabilizar o processo de ensino-aprendizagem em tempos de isolamento social (SANTIAGO et al., 2021). Essa experiência diferente, apesar de demandar muitas adaptações, representa uma grande oportunidade de inovação na forma de ensinar e aprender, e essas experiências podem ter chegado para ficar quando as atividades presenciais retornarem, aproveitando essa grande quantidade de material produzido e disponível constantemente.

Os resultados obtidos ajudam a chamar a atenção sobre a necessidade da aplicação das metodologias ativas de ensino-aprendizagem nas disciplinas, tanto dos eixos básicos dos cursos de engenharia como das matérias específicas e profissionalizantes, e que dessa forma sirvam de incentivo para uma incorporação ainda maior de experiências inovadoras na sala de aula. Por outro lado, também se faz necessário atualizar as formas de avaliação das disciplinas, assim como vinculálas corretamente a essas atividades e explorar alternativas que fomentem a interação 
e experimentação ativa do aluno com o conteúdo. Nesse sentido, cabe destacar, portanto, o imperativo de planejar adequadamente as atividades e recursos precisos e de procurar a participação direta, responsável e consciente dos discentes, vinculando os objetivos procurados com as competências que são exigidas pelo mercado de trabalho.

Figura 11 - Nuvens de palavras a partir das respostas dos professores sobre a questão "Quais recursos didáticos utiliza para ministrar os conteúdos teóricos e práticos das suas disciplinas?". (a) Atividades práticas em formato presencial. (b) Conteúdos teóricos em formato presencial. (c) Aulas em formato remoto
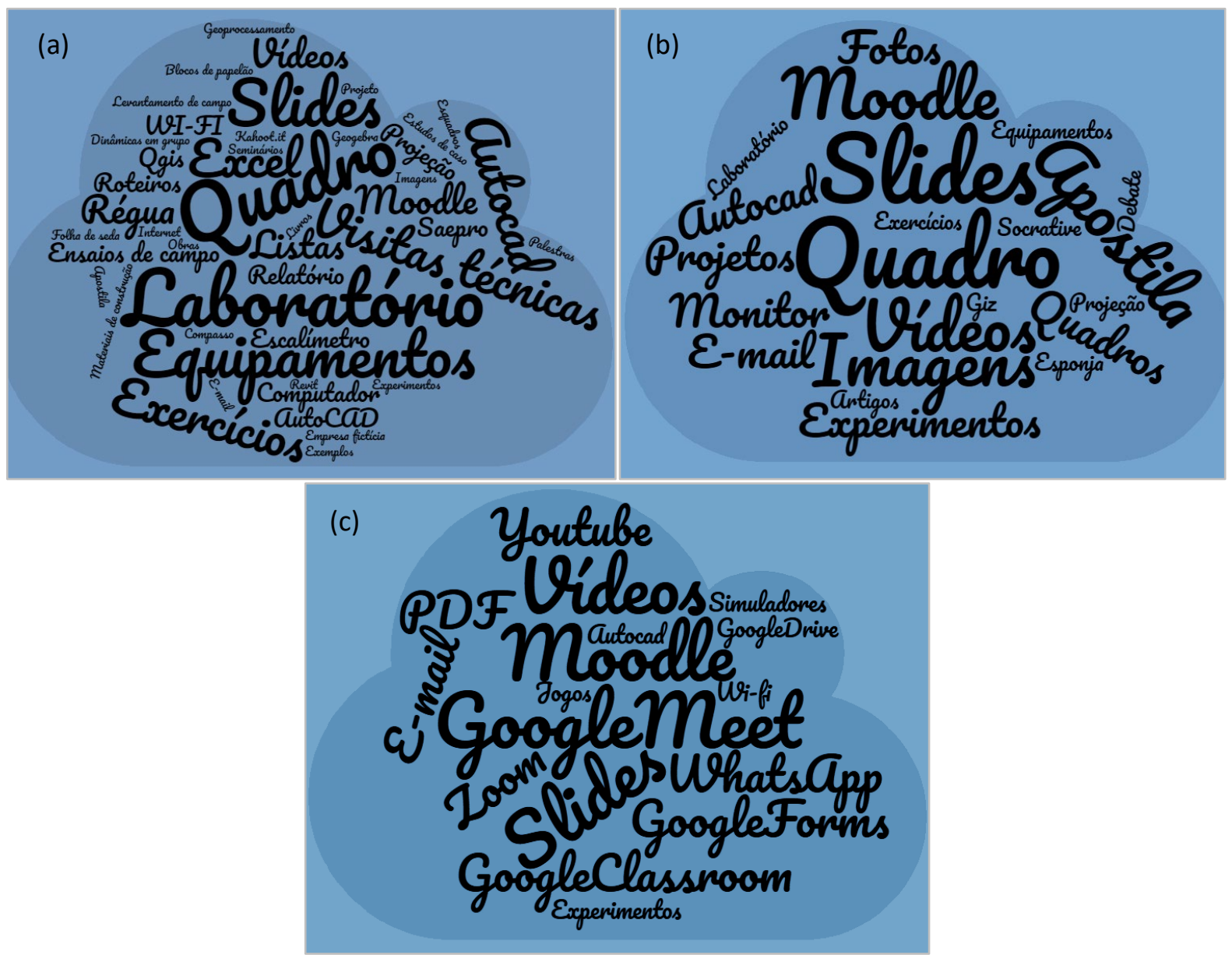

Fonte: os autores.

\section{Conclusões}

A utilização de metodologias ativas de ensino-aprendizagem nas Universidades é cada vez mais necessária para uma formação completa dos profissionais da engenharia, diante dos desafios impostos pelos problemas de evasão e baixo desempenho acadêmico dos estudantes. Atualmente, com a pandemia de COVID-19 e a obrigação de adaptar o ensino formal para a modalidade remota, a exigência dessa modernização de recursos didático-pedagógicos e de abordagem de conteúdos toma força. Assim, o objetivo deste estudo voltou-se à análise das percepções de docentes e discentes sobre a aplicação de metodologias ativas em disciplinas de graduação do curso de Engenharia Civil da Universidade Federal de Santa Maria no contexto atual, em comparação com experiências prévias em formato tradicional presencial. 
Para isso, foram realizadas análises qualitativas e quantitativas das opiniões facilitadas pelos alunos a partir de formulários de pesquisa e pelos professores mediante entrevistas estruturadas, em relação com o uso dessas metodologias. Os resultados permitiram comprovar que a incorporação de tecnologia, conteúdos audiovisuais e ferramentas para fomentar a interação e motivação dos alunos se tornaram aspectos fundamentais nas atividades, tanto em formato presencial quanto remoto. Além disso, a resolução de problemas com redação de projetos e documentos técnicos, o trabalho em equipe e o inter-relacionamento entre os discentes apareceram como as principais estratégias incorporadas pelos docentes nas disciplinas. Assim, metodologias como Project Based Learning e Team Based Learning foram as que mais se destacaram positivamente no curso, por sua implementação ser facilitada pela adaptação com os conteúdos didáticos das disciplinas e por contribuir positivamente no desenvolvimento de competências necessárias para os futuros engenheiros. Desse modo, tanto alunos como professores perceberam essas metodologias ativas como grandes contribuintes no aprendizado, de forma separada, mas sobretudo também coordenadas entre elas

Por outro lado, pôde-se notar que as poucas discordâncias para com as metodologias ativas evidenciaram-se em estudantes de semestres mais iniciais, que ainda não puderam ter contato com disciplinas mais práticas e profissionalizantes e com o uso dessas estratégias inovadoras. Dentre as metodologias, as principais ressalvas dos alunos concentraram-se na sala de aula invertida e avaliação entre pares e, em menor medida, na gamificação, o que pode exigir uma maior necessidade de adaptação às particularidades das atividades, de cuidado na implementação e de explicação dos objetivos pretendidos com essas inciativas.

Ademais, segundo opinião dos professores, evidenciou-se que, além de um bom planejamento prévio, a interação e o envolvimento do estudante é essencial para o sucesso da implementação da metodologia ativa. Em relação às mudanças derivadas pela brusca migração das aulas para o formato remoto ocasionada pela pandemia, identificaram-se muitas alterações nas abordagens e recursos utilizados pelos professores, com grande destaque para as plataformas de ensino a distância e as tecnologias em rede. Porém, também percebeu-se um elevado distanciamento entre docentes e discentes, o que, além de gerar desânimo em todos os atores do processo de ensino-aprendizagem, dificulta enormemente a realização de atividades de forma mais prática e efetiva nesses ambientes virtuais.

Assim, com o destaque às oportunidades e debilidades encontradas nas análises das percepções de docentes e discentes, os resultados obtidos neste trabalho podem ser úteis para incentivar a utilização de metodologias ativas nos cursos de ensino tecnológico, de forma a promover experiências motivadoras no contexto atual, além de melhorar a formação dos estudantes de engenharia. Como trabalhos futuros, sugere-se o estudo dessas percepções em cursos de Engenharia Civil de outras instituições de ensino, além da sua análise em outros cursos da área tecnológica. Pode-se ainda, investigar de forma mais profunda as mudanças nos métodos de ensino e os resultados da aplicação de metodologias ativas no formato remoto, assim como as inovações adotadas quando o ensino presencial voltar, em função da experiência desenvolvida no ambiente virtual.

8




\section{Referências}

ALANNE, K. An overview of game-based learning in building services engineering education. European Journal of Engineering Education, v. 41, n. 2, p. 204-219, 2016.

BARBOSA, E. F.; MOURA, D. C. Metodologias ativas de aprendizagem no ensino de Engenharia. XIII International Conference on Engineering and Technology Education. Guimarães, Portugal, 2014.

BODNAR, C. A.; CLARK, R. M. Can game-based learning enhance engineering communication skills? IEEE Transactions on Professional Communication, v. 60, n. 1, p. 24-41, 2017.

CHENG, K. H.; HOU, H. T.; WU, S. Y. Exploring students' emotional responses and participation in an online peer assessment activity: A case study. Interactive Learning Environments, v. 22, n. 3, p. 271-287, 2014.

COHEN, J.; ROBINSON, C. Enhancing teaching excellence through team-based learning. Innovations in Education and Teaching International, v. 55, n. 2, p. 133 142, 2018.

COSTA, C. B. Autoavaliação e avaliação pelos pares: uma análise de pesquisas internacionais recentes. Revista Diálogo Educacional, v. 17, n. 52, p. 431, 2017.

COSTA, L. A. C. Desafios e avanços educacionais em tempos da COVID-19: a docência no Ensino Remoto em cursos de Engenharia. Revista de Estudos e Pesquisas sobre Ensino Tecnológico (EDUCITEC), v. 6, e152920, 2020.

DESHPANDE, A. A.; HUANG, S. H. Simulation games in engineering education: A state-of-the-art review. Computer Applications in Engineering Education, v. 19, n. 3, p. 399-410, 2011.

GUO, P.; SAAB, N.; POST, L. S.; ADMIRAAL, W. A review of project-based learning in higher education: Student outcomes and measures. International Journal of Educational Research, v. 102, n. May, p. 101586, 2020.

IGLESIAS-PRADAS, S.; HERNANDEZ-GARCÍA, A.; CHAPARRO-PELÁEZ, J.; PRIETO, J. L. Emergency Remote Teaching and Students' Academic Performance in Higher Education during the COVID-19 Pandemic: A Case Study. Computers in Human Behavior, v. 119, n. January, p. 106713, 2021.

JEONG, J. S.; GONZÁLEZ-GÓMEZ, D.; CAÑADA-CAÑADA, F.; GALLEGO-PICÓ, A.; BRAVO, J. C. Effects of active learning methodologies on the students' emotions, selfefficacy beliefs and learning outcomes in a science distance learning course. Journal of Technology and Science Education, v. 9, n. 2, p. 217-227, 2019.

KOLB, D. A. Experiential learning: experience as the source of learning and development. Englewood Cliffs, New Jersey: Prentice-Hall, 1984.

KOLHEKAR, M.; SHAH, M.; JADJAV, A. Engaging students actively for effective teaching-learning. Journal of Engineering Education Transformations, v. 34, $\mathrm{n}$. Special Issue, p. 407-416, 2021.

KURI, N. P. Tipos de Personalidade e Estilos de Aprendizagem: Proposições para o Ensino de Engenharia. 2004. 324 f. Tese (Doutorado). Universidade Federal de São Carlos. São Carlos, 2004. 
LUCIANO, B.; ALVES, C.; LIMA, S. F. Team-Based Learning as a Collaborative Learning Form and Flipped Classroom with Process. Revista Brasileira de Educação Médica, v. 42, n. 4, p. 86-95, 2018.

PRINCE, M. Does Active Learning Work? A Review of the Research. Journal of Engineering Education, v. 93, n. July, p. 223-231, 2004.

NAJDANOVIC-VISAK, V. Team-based learning for first year engineering students. Education for Chemical Engineers, v. 18, p. 26-34, 2017.

POURMAND, P.; PUDASAINI, B.; SHAHANDASHTI, M. Assessing the Benefits of Flipped Classroom in Enhancing Construction Students' Technical Communication Skills. Journal of Civil Engineering Education, v. 147, n. 1, p. 04020010, 2021.

RICAURTE, M.; VILORIA, A. Project-based learning as a strategy for multi-level training applied to undergraduate engineering students. Education for Chemical Engineers, v. 33, p. 102-111, 2020.

SERGIS, S.; SAMPSON, D. G.; PELLICCIONE, L. Investigating the impact of Flipped Classroom on students' learning experiences: A Self-Determination Theory approach. Computers in Human Behavior, v. 78, p. 368-378, 2018.

SHARMA, A. ; DUTT, H.; SAI, C. N. V.; NAIK, S. M. Impact of project based learning methodology in engineering. Procedia Computer Science, v. 172, p. 922-926, 2020.

STEFANELLO, V.; OESTREICH, L.; ROSA, C. B.; RUIZ-PADILLO, A. Análise do perfil de aprendizagem dos estudantes de um campus universitário tecnológico a partir da aplicação de metodologias ativas. Revista de Estudos e Pesquisas sobre Ensino Tecnológico (EDUCITEC), v. 6, e098320, 2020.

SUN, D. L.; HARRIS, N.; WALTHER, G.; BAIOCCHI, M. Peer assessment enhances student learning: The results of a matched randomized crossover experiment in a college statistics class. PLoS ONE, v. 10, n. 12, p. 1-8, 2015.

UFSM. UFSM em números. Santa Maria, 2020. Disponível em https://portal.ufsm.br/ufsm-em-numeros/publico/index.html. Acesso em: 29 de outubro de 2020.

VENTURA, L. M. Análise de jogos e recursos gamificados utilizados para mediar o processo de ensino-aprendizagem de docentes em curso de formação. Revista de Estudos e Pesquisas sobre Ensino Tecnológico (EDUCITEC), v. 7, e131321, 2021.

ZAPPE, S.; LEICHT R.; MESSNER, J.; LITZINGER, T.; LEE, H. W. "Flipping" the Classroom To Explore Active Learning in a Large Undergraduate Course. ASEE Annual Conference and Exposition, Conference Proceedings, 2009. 
Recebido: $14 / 04 / 2021$

Aprovado: $17 / 11 / 2021$

Como citar: RENOSTO, A. F. et al. Estudo das percepções de docentes e discentes sobre a aplicação de metodologias ativas em disciplinas de graduação em Engenharia Civil. Educitec Revista de Estudos e Pesquisas sobre Ensino Tecnológico, v. 7, e170921, 2021.

Contribuição de autoria:

Amanda Furlin Renosto: Análise formal, metodologia, visualização, escrita (rascunho original).

Luiza Pereira Antunes: Análise formal, visualização, escrita (rascunho original).

Eloísa Moura Somavilla: Análise formal, visualização, escrita (rascunho original).

Alejandro Ruiz-Padillo: Conceituação, aquisição de financiamento, metodologia, administração de projeto, escrita (revisão e edição).

Editor responsável: landra Maria Weirich da Silva Coelho

Direito autoral: Este artigo está licenciado sob os termos da Licença Creative CommonsAtribuição 4.0 Internacional

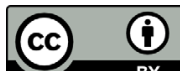

